\title{
Surface Properties and Maximum Insertion Energy of Sterilized Orthodontic Mini-Implants with Different Chemical Materials
}

\author{
SILVIA IZABELLA POP1, RADU CHIOREAN², DANA CRISTINA BRATU³, MARIANA PACURAR ${ }^{2 *}$, VIOLETA MERIE ${ }^{4}$, \\ DANIELA MANUC ${ }^{5}$, EDWIN SEVER BECHIR ${ }^{1}$, ELINA TEODORESCU ${ }^{6}$, VIORICA TARMURE ${ }^{7}$, MIRCEA DUDESCU ${ }^{2}$ \\ ${ }^{1}$ University of Medicine and Pharmacy Tirgu-Mures, Faculty of Dentistry, Department of Orthodontics, 38 Gheorghe Marinescu \\ Str., 540139 Tirgu Mures, Romania \\ ${ }^{2}$ Technical University of Cluj-Napoca, Department of Mechanical Engineering, 28 Memorandumului Str, 400114 Cluj Napoca, \\ Romania \\ ${ }^{3}$ University of Medicine and Pharmacy Victor Babes Timisoara, Faculty of Dentistry, Department of Orthodontics, Faculty of \\ Dentistry, 9 Revolutiei din 1989 Blv, 300041 Timisoara, Romania \\ ${ }^{4}$ Technical University of Cluj Napoca, Department of Materials Science and Engineering, 28 Memorandumului Str, 400114 Cluj \\ Napoca, Romania \\ EUniversity of Medicine and Pharmacy Carol Davila Bucharest, Faculty of Dentistry, Department of Public Health, 37 Dionisie \\ Lupu Str., 030167 Bucharest, Romania \\ ${ }^{6}$ University of Medicine and Pharmacy Carol Davila, Department of Orthodontics, 4-6 Eforie Str., 050037, Bucharest, Romania \\ ${ }^{7}$ University of Medicine and Pharmacy Iuliu Hatieganu of Cluj-Napoca, Faculty of Dentistry, Department of Orthodontics, 33 \\ Motilor Str, 400001 Cluj Napoca, Romania
}

\begin{abstract}
The main objective of the present study was to evaluate the maximum insertion energy and the surface topography of the Yes Anchor (Orlus TM) orthodontic mini-implants subject to various cleaning and sterilization procedures. A total of 50 orthodontic mini-implants divided in 5 groups were subjected to testing. The only one significant difference $(p=0.04)$ of the maximum insertion energy was observed between groups YA1 and YA3.
\end{abstract}

Keywords: mini-implants, orthodontics, sterilization

The mini-implants are temporary anchor devices commonly used in the contemporary orthodontic therapy; their major advantage is the possibility of immediate loading and their non-traumatic insertion. Although their success rate is about $85 \%$ [1.2], their reinsertion is often necessary, especially due to the change in biomechanics during the orthodontic treatment [3]. Also, the reuse of mini-implants is common, especially in the developing countries, due to their fairly high-price. To prevent contamination and infection, the reinsertion of the miniimplants must be preceded by effective cleaning and sterilization procedures. These procedures can interfere with most of the mechanical and surface characteristics of the mini-implants. The evaluation of the efficiency of ultrasonic, electrolytic and chemical cleaning procedures had been made in several studies [4-6], but in the Romanian literature, we found no study regarding the testing of the mechanical properties of the mini-implants after sterilization. Another important aspect studied in several papers [9-16] is the changes made by the sterilization and insertion procedures to the properties of temporary anchor devices. The studied properties were different, including the characteristics related to implants' stability (maximum insertion, removal torque) [9, 11-13], the mechanical characteristics (the fracture torque) [10, 17 or the surface characteristics (roughness, topography) $[14,15]$.

The connection between the number of sterilizations and the modification of the insertion torque, removal and fracture torque was made by Noorollahian et al. [16]. His study [16], however, does not include additional cleaning procedures such as sandblasting or ultrasonic cleaning. Estelita et al. [17], have studied the modification of the mechanical resistance of the mini-implants, purchased from a single manufacturer, subjected to 3 types of cleansing and disinfection treatments. Thus, we consider it useful to carry out an experimental study that includes both the evaluation of the surface changes of the miniimplants and their maximum insertion energy after their reinsertion and sterilization.

The main objective of the present study is to evaluate the maximum insertion energy and the surface topography of the Yes Anchor (Orlus TM) orthodontic mini-implants subject to various cleaning and sterilization procedures. The secondary objective is to highlight the differences in the properties of these mini-implants derived from sterilization procedures and to determine the optimal sterilization method with minimal damage of the mechanical properties and, implicitly, its clinical efficacy.

\section{Experimental Part \\ Material and Method}

A total of 50 orthodontic mini-implants of the size of 1.6 $x 8 \mathrm{~mm}$ were subjected to testing. These temporary anchor devices were purchased from Orlus via their local Dental Focus representative from Bucharest. The mini-implants were divided into 5 categories as follows: YAO $(n=10)$, new, unused mini implants, YA1 $(n=10)$ mini implants inserted into a swine mandible (fig. 1), removed, subject to ultrasonic cleansing and sterilization in the autoclave, YA2 $(n=10)$ mini-implants inserted into a swine mandible, removed, cleansed by applying a 37\% phosphoric acid gel, for $10 \mathrm{~min}$, followed by an immersion into a $5.25 \%$ sodium hypochlorite solution for $30 \mathrm{~min}$, sterilization in an autoclave, YA3 $(n=10)$ mini-implants inserted into a swine mandible, removed, subject to cleansing by washing, sandblasting

\footnotetext{
*email: marianapac@yahoo.com; Phone:0744952183
} 
with aluminum oxide, and sterilization in an autoclave, YA4 ( $n=10)$ mini-implants inserted into a swine mandible, removed, washed with distilled water and sterilized in an autoclave.

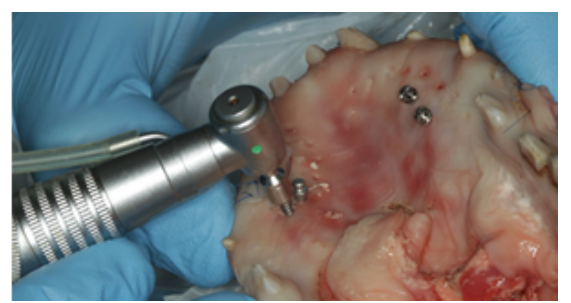

Fig. 1. The insertion of mini-implants from YA1-YA4 groups into swine mandible

As a method, the new mini-implants (YAO) and those undergoing various cleaning and sterilization procedures (YA1, YA2, YA3, YA4) were inserted into an artificial bone with a density of $0.80 \mathrm{~g} / \mathrm{cm} 3$ of about $1 \mathrm{~cm}^{3}$ to determine the maximum insertion energy. The insertion in the bone blocks was performed at a 90-degree angle using a screw driver mounted in the Instron 3366 Universal Testing Machine, $10 \mathrm{kN}$ (from the Department of Materials' Resistance, Faculty of Mechanics from Cluj Napoca, Romania) equipped with an Instron Bluehill 2 software (fig. 2).

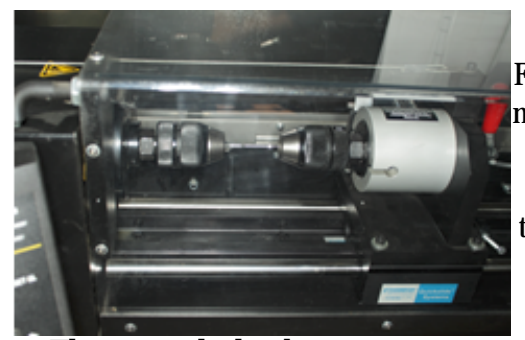

Fig. 2. The insertion of the mini-implants into artificial bone blocks using a screwdriver mounted in the Instron 3366 Universal Testing Machine

The recorded values were registered in Excel tables and were subjected to statistical descriptive analysis, the statistical tests used being Student T and Anova, significance threshold of 0.05 . Also, a microscopic analysis of the mini-implants had been done, both of the intraosseous inserted area and of the head of the implant, by means of optical microscopy methods to determine the degree of alteration in their morphology. An Olympus GX 51 optical microscope, magnification from $\times 20$ to $\times 100$, was used to highlight the micro-morphological characteristics of the surface of the spirals and of the head of the mini-implants.

\section{Results and discussions}

The mean values of the maximum insertion energy for the five groups, as well as the standard deviations, are shown in table 1.

Table 1

THE MEAN VALUES OF THE MAXIMUM INSERTION ENERGY FOR

THE FIVE GROUPS AS WELL AS THE STANDARD DEVIATIONS

\begin{tabular}{|c|c|}
\hline $\begin{array}{c}\text { Group of mini- } \\
\text { implants }\end{array}$ & $\begin{array}{c}\text { Maximum insertion } \\
\text { energy value and its } \\
\text { standard deviation (J) }\end{array}$ \\
\hline YA0 & $13.96 \pm 2.17$ \\
\hline YA1 & $15.45 \pm 1.79$ \\
\hline YA2 & $13.42 \pm 1.14$ \\
\hline YA3 & $11.99 \pm 2.77$ \\
\hline YA4 & $14.48 \pm 91$ \\
\hline
\end{tabular}

The $p$-values of the statistical analysis of the maximum insertion energy of the 5 mini-implant groups and the statistical comparison between groups are shown in table 2.

The only one significant difference $(p=0.04)$ of the maximum insertion energy was observed between groups YA1 and YA3.

The microscopic images of the YAO mini-implants are shown in figure 3. It can be seen that the surface of the
Table 2

THE $p$-VALUES OF THE STATISTICAL ANALYSIS OF THE MAXIMUM INSERTION ENERGY

\begin{tabular}{|l|l|l|l|l|l|}
\hline & YA0 & YA1 & YA2 & YA3 & YA4 \\
\hline YA0 & - & 0.2716 & 0.6349 & 0.2461 & 0.637 \\
\hline YA1 & & - & 0.0649 & $\mathbf{0 . 0 4 7 1}$ & 0.3115 \\
\hline YA2 & & & - & 0.3171 & 0.1432 \\
\hline YA3 & & & & - & 0.0928 \\
\hline YA4 & & & & & - \\
\hline
\end{tabular}

new Yesanchor mini-implants has shown some structural strains and defects, probably resulting from the manufacturing process.

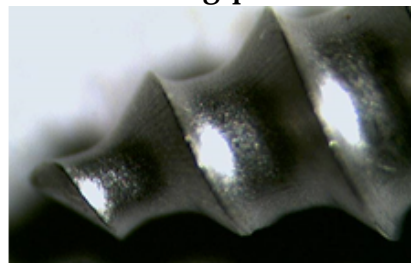

Fig. 3 The optical image of the mini-implant from the YAO group

Figure 4 shows the surface morphology at a magnification of $X 20$ of the mini-implants from group YA1. No major debris of organic tissue can be detected, although the top of the spires presents defects from place to place.

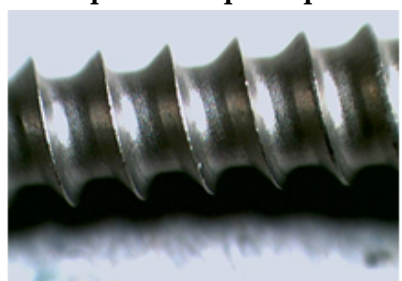

Fig. 4 The optical image of the mini-implant from the YAl group

Clear signs of chemical corrosion are evident on the surface of the mini-implants from the YA2 group (fig. 5).

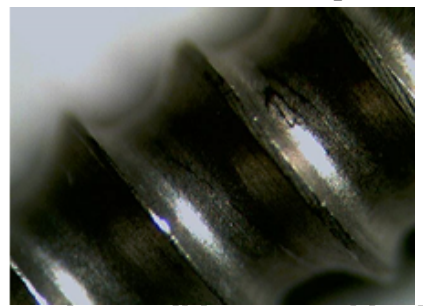

Fig. 5 The optical image of the mini-implant from the YA2 group

The sandblasting visibly altered the surface topography of the mini-implants from the YA3 group (fig. 6). Their surace appeared rougher, but no tissue debris was detected. Also, the mini-implants' spirals showed some defects, probably due to their reinsertion.

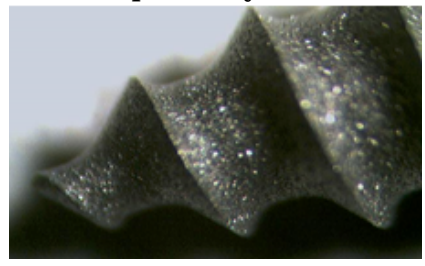

Fig. 6 The optical image of the mini-implant from the YA3 group

The microscopic image of the autoclaved mini-implants from the YA4 group showed organic debris, especially on the outer edges (fig. 7).

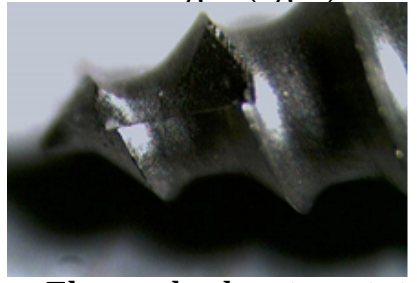

Fig. 7 The optical image of the mini-implants from the YA4 group

The orthodontic mini-implants are used in the orthodontic therapy as anchoring skeletal auxiliaries. For patients coming from developing countries, the major disadvantage of these temporary anchorages devices is their high price, especially when more than one device is 
required during the orthodontic treatment. The sterilization and the reuse of mini-implants is a way to improve the effectiveness/cost ratio.

The relocation of a mini-implant is possible only when the structural integrity is preserved and the mechanical properties have not been affected by sterilization and cleaning procedures. This present study was unable to detect significant changes from the statistical point of view, in the maximum insertion energy of the mini-implants, excepting a statistically significant $p$ value $(0.04)$ between the ultrasonically cleaned and sandblasted implants. The aluminum oxide sandblasting has been recommended by several authors [19-24] as a method of increasing the surface roughness of the implants, and implicitly of increasing their primary stability. The studies show $[3,22]$, that this procedure can increase the fracture torque, but not the insertion torque. In our study, the sandblasting decreased the value of the maximum insertion energy, when compared to the new mini-implants.

Kumar's studies [5] show that a simple washing is not always sufficient as a pre-sterilization cleaning method. The microscopic images of the mini-implants from the YA4 group confirm this, much organic debris being observed there. As a method of sterilization, the sterilization in the autoclave is the most often used and recommended method by the ISO specifications (ISO 17665). The miniimplants (YA4) that have been sterilized in the autoclave without being subjected to any other chemical or abrasive cleaning (sandblasting) have shown some organic debris on the surface of the spirals. We can, therefore, conclude that additional pre-sterilization cleaning procedures are required. Our results are the same with those of Noorollahian [6], underlining the need for chemical preparation (with phosphoric acid and sodium hypochlorite) of the implants, before autoclaving them. Another aspect that has been studied $[6,9,11-19]$ is the impairment of biocompatibility of the mini-implants after the use of chemicals, with the appearance of corrosion signs. Indeed, on the surface of the mini-implants from the YA2 group, signs of chemical corrosion were noted, with no large extension of these defects.

Regarding the surface parameters that have been observed, we could state that sandblasting made visible changes in morphology of the mini-implants. From this point of view our study had similar results to that of El-Wasefi [24]. While the insertion torque is an indicator of the primary stability of the mini-implants, the maximum insertion energy shows the ease with which a mini-implant can be inserted. The significant decrease of the maximum insertion energy can be attributed to the used method (sandblasting), but extensive studies are needed to investigate this issue. The most important characteristic in using dental biomaterials are their biocompatibility $[25,26]$. The results of Pop [27] on properties of epoxy coated NiTi open coil springs indicated that aesthetic coating might affect their stiffness. Researches of Zegan et al [28], focused on the orthodontic mini-implant coated with silver doped hydroxyapatite, observed that nanoparticles deposition on titanium surface of miniimplants offers the possibility design structural and morphological features on nanoscale.

\section{Conclusions}

The chemical and mechanical cleaning procedures, followed by an autoclave sterilization of the mini-implants from the YA1, YA2 and YA4 group did not cause any statistically significant change of the maximum insertion energy, sandblasting followed by sterilization significantly decreased this parameter of the mini implants from the YA3 group.

The autoclave sterilization preceded by rinsing with water (YA4) and the ultrasonic cleaning of the mini- implants does not completely eliminate the organic debris on their surface.

A chemical corrosion could be observed on the surface of the chemically cleaned mini-implants.

Acknowledgment: This work was supported by the University of Medicine and Pharmacy of Tirgu Mures, Research Grant number 17800/13/22/12/2015.

\section{References}

1.J ANSON, G., GIGLIOTTI, M.P., ESTELITA, S., CHIQUETO, K., Internat J Oral and Maxillofac Surgery, 2013, vol. 42, no. 4, pp. 527-534

2.WIECHMANN, D., MEYER, U., BUCHTER, A., Clinic Oral Impl Research, 2007, vol.18, no. 2, pp. 263-267

3.CHUNG, K.-R, CHOO, H., KIM, S.-H., NGAN, P., Am J of Orthod and Dentofac Orthop, 2010, vol. 138, no. 6, pp. 839-849

4.PARK, J.H, OLIVARES-NAVARRETE, R., BAIER, R.E., Acta Biomater, 2012, vol. 8, no. 5, pp. 1966-1975

5. KUMAR, S., LEE, W.T., SZILI E.J., J of Hospital Infect, 2012, vol. 81, no. 1, pp. 41-49

6.NOOROLLAHIAN, S., ALAVI, S., MONIRIFARD, M., Dent Research J, 2012, vol. 9, no. 4, pp. 447-451

7.BAGG, J., SMITH, A.J., HURRELL, D., MCHUGH, S., IRVIN, G., Brit Dental J, 2007, vol. 202, no. 9, article E22

8.WHITWORTH, C.L., MARTIN, M.V., GALLAGHER, M., WORTHINGTON, H.V., Brit Dent J, 2004, vol. 197, no. 10, pp. 635-640 9.AKYALCIN, S., MCIVER, H.P., ENGLISH. J.D., ONTIVEROS, J.C., GALLERANO, R.L., 2013, Angle Orthod, vol.83, no. 4, pp. 674-679 10.MATTOS, C.T., RUELLAS, A.C., SANT'ANNA, E.F., J of Orthod, 2011 vol.38, pp.15-20

11.CHO, K., BAEK, S., Angle Orthod, 2012, vol. 82, pp. 618-624

12. HEO, Y., CHO, K., BAEK, S., Angle Orthod, 2012, vol.82, pp. 881888

13.SHAH, A.H., BEHRENTS, R.G., KIM, K.B., KYUNG, H.M., BUSCHANG, P.H., Angle Orthod, 2012, vol. 82, pp. 603-610

14.SEBBAR, M., BOURZGUI, F., LAZRAK, L., AAZZAB, B., EL QUARS, F., Revue de Stomatologie et de Chirurgie Maxillo-Faciale, 2012, vol. 113, no. 5, pp. 365-369

15. SEBBAR, M., BOURZGUI, F., AAZZAB, B., ELQUARS, F., Internat Orthod, 2011, vol. 9, no. 3, pp. 325-338

16.NOOROLLAHIAN, S., ALAVI, S., RAFIEI, E., Dental Research J, 2015, vol. 12, no. 3, pp. 243-247

17.ESTELITA, S., JANSON, G., CHIQUETO, K., FERREIRA, E.S., Internat J of Dent, 2014, http://dx.doi.org/10.1155/2014/424923

18.KIM, S., CHO, J., CHUNG, K., KOOK, Y., NELSON, G., Am J of Orthod and Dentofac Orthoped, 2008, vol. 134, no. 1, pp. 36-43

19.CHANG, Y.L., BAEK, S.H., Angle Orthod, 2012, vol 82, no. 4, pp. 611617

20.SCHWARTZ, Z, LOHMANN, C.H., BLAU, G., BLANCHARD, C.R., SOSKOLNE, A.W., LIU, Y., et al., Clin Oral Implants Res., 2000, vol 11, pp. 183-194

21.MOON, C.H., LEE, D.G., LEE, H.S., IM, J .S., BAEK, S.H., Angle Orthod., 2008, vol 78, pp 101-106

22.CHENG, S.J., TSENG, I.Y., LEE, J.J., KOK, S.H., Int J Oral Maxillofac Implants, 2004, vol 19, pp 100-106

23.LIM, S.A., CHA, J.Y., HWANG, C.J ., Angle Orthod, 2008, vol 74, pp. 234-240

24.EL-WASSEFY, N., EL-FALLAL, A., TAHA, M., Angle Orthod. 2015, vol 85, pp. 39-47

25.BECHIR, A., PACURAR, M., PODARIU, A.C., MUCENIC, S., BECHIR, E.S., Rev. Chim. (Bucharest), 65, no.1, 2014, pp. 110-112

26.HANCU, V., COMANEANU, R.-M., COMAN, C., FILIPESCU, A.-G., GHERGIC, D.L., COTRUT, M.C., Rev. Chim. (Bucharest), 65, no.6, 2014, pp. 706-709

27.POP, S.I., BRATU, D.C., KONCZ, K., DUDESCU, M., ESIAN, D., SIMON, C., ARDELEAN L., Rev.Chim.(Bucharest), 67, no. 5, 2016, pp. 10011003

28.ZEGAN, G, CARAUSU, EM, GOLOVCENCU, L, SODOR BOTEZATU, A, CERNEI, ER, ANISTOROAEI, D, Rev. Chim.(Bucharest), 68, no. 12, 2017, p. 2929

Manuscript received: 10.03 .2018 